
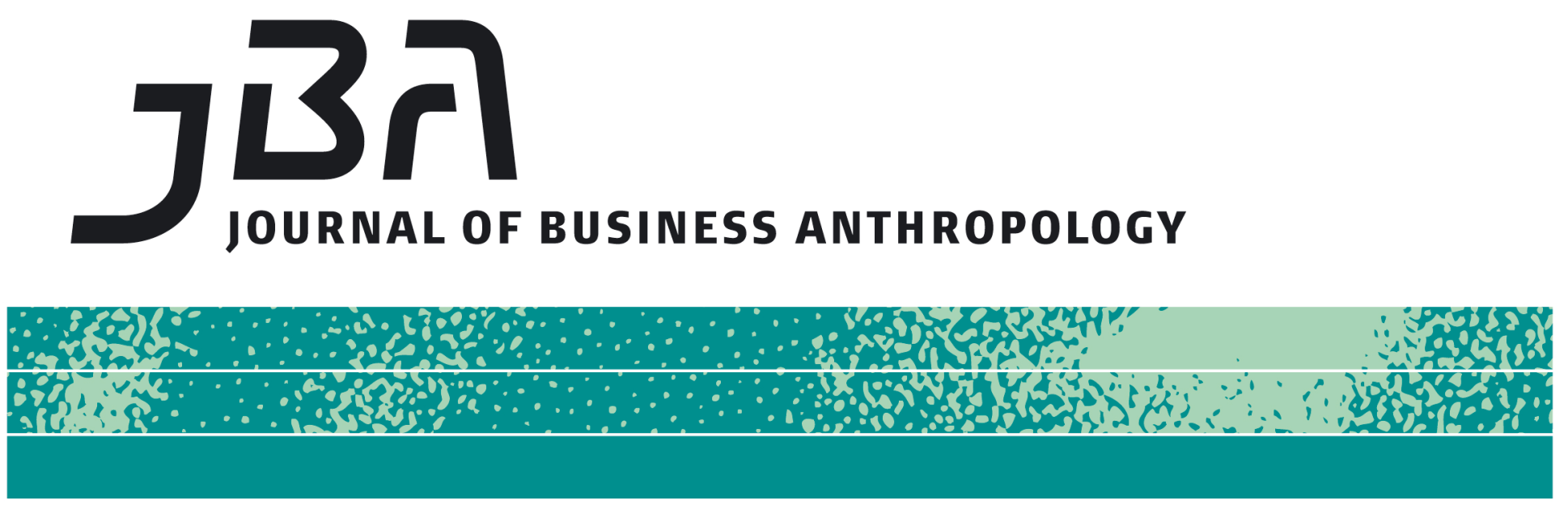

\title{
The Editor's Two Cents
}

\author{
Greg Urban
}

Here is a promise I'll make (and hope to keep): Not every issue of JBA will start with a note from this editor. However, some new and exciting developments just cry out to be communicated. One of them is the Global Business Anthropology Summit. Allen Batteau of Wayne State University is convening a meeting of prominent figures in business anthropology, asking them to "confront head-on the divide between academic anthropology and practicing anthropology, and to recognize both that academic anthropology can produce practical results and that practicing

Page 1 of 2

JBA 7(1): 1-2

Spring 2018

(C) The Author(s) 2018

ISSN 2245-4217

www.cbs.dk/jba anthropology can contribute to theoretical development. "Stay tuned.

We christen with this issue as well a new occasional section, Readers' Corner. We're intentionally not calling it "book reviews" because we don't want to receive books from publishers and then hunt for reviewers. The idea is rather to establish a forum for reflections on previously published work, including but not limited to books. The reflections will NOT be subjected to our familiar double blind review process, but they will undergo our in-house review, and we reserve the right to reject or request modifications. Don't expect to see this section each issue, but feel free to contribute as the spirit moves you.

In this issue we also feature our second in the intermittent series entitled Notes from the Corner Office, designed to open a channel for feedback from present or former upper level executives about matters relevant to business anthropology. This issue's note comes to us courtesy of Dr. Lawrence ("Larry") Coben, current Chairman of the Board at NRG 
Energy, and also a PhD anthropologist, specializing in highland South American archaeology. Larry founded and directs the Sustainable Preservation Initiative. He has much to teach us about applying a business sense to culture as well as a cultural sense to business. His piece complements this issue's theme: Implementation. As you'll see, the articles here come from a range of anthropologists - on the one side, Maryann McCabe, who researched middle class Americans doing laundry - her purpose was to change advertising practice - to, on the other side, Kerry Fosher, who seeks to integrate social scientists into decisionmaking within the Marine Corps. Need I add how crucial implementation is for business anthropologists?

Lastly, if all works out as planned (and how often does that happen?), we will soon (not saying when) inaugurate a new occasional section aimed at giving millennials a voice to make known to readers how they view business anthropology. We will peer into the future of our field, so to speak, through the eyes of the generation of the future.

And so without further ado, we bring you JBA volume 7, issue 1: 